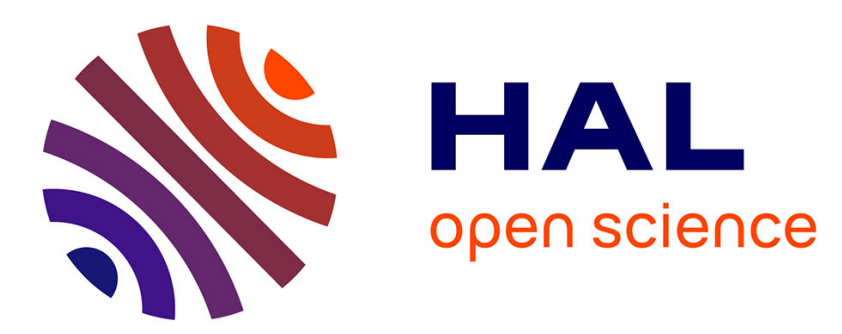

\title{
Vibration-induced Liquefaction of Granular Suspensions
}

Caroline Hanotin, Sébastien Kiesgen de Richter, Philippe Marchal, Laurent J.

Michot, Christophe Baravian

\section{To cite this version:}

Caroline Hanotin, Sébastien Kiesgen de Richter, Philippe Marchal, Laurent J. Michot, Christophe Baravian. Vibration-induced Liquefaction of Granular Suspensions. Physical Review Letters, 2012, 108 (19), pp.198301. 10.1103/PhysRevLett.108.198301 . hal-00778481

\section{HAL Id: hal-00778481 \\ https://hal.science/hal-00778481}

Submitted on 24 Jan 2022

HAL is a multi-disciplinary open access archive for the deposit and dissemination of scientific research documents, whether they are published or not. The documents may come from teaching and research institutions in France or abroad, or from public or private research centers.
L'archive ouverte pluridisciplinaire HAL, est destinée au dépôt et à la diffusion de documents scientifiques de niveau recherche, publiés ou non, émanant des établissements d'enseignement et de recherche français ou étrangers, des laboratoires publics ou privés.

\section{(c)(1)}

Distributed under a Creative Commons Attribution| 4.0 International License 


\title{
Vibration-induced liquefaction of granular suspensions
}

\author{
C. Hanotin, ${ }^{1, *}$ S. Kiesgen de Richter, ${ }^{1}$ P. Marchal, ${ }^{2}$ L.J. Michot, ${ }^{3}$ and C. Baravian ${ }^{1, \dagger}$ \\ ${ }^{1}$ Laboratoire d'Energétique et de Mécanique Théorique et Appliquée (LEMTA), \\ Université de Lorraine, CNRS (UMR 7563), 2 Avenue de la Forêt de Haye, \\ BP160, 54504 Vandoeuvre Lès Nancy Cedex, France. \\ ${ }^{2}$ Laboratoire Réactions et Génie des Procédés (LRGP-GEMICO), \\ Université de Lorraine, 1 rue Grandville, BP 20451, 54001 Nancy, France. \\ ${ }^{3}$ Laboratoire Environnement et Minéralurgie (LEM), Université de Lorraine, \\ CNRS (UMR 7569), BP40, 54501 Vandoeuvre Lès Nancy Cedex, France.
}

(Dated: February 20, 2012)

\begin{abstract}
We investigate the mechanical behavior of granular suspensions subjected to coupled vibrations and shear. At high shear stress, whatever the mechanical vibration energy and bead size, the system behaves like a homogeneous suspension of hard spheres. At low shear stress, in addition to a dependence on bead size, vibration energy drastically influences the viscosity of the material that can decrease by more than two orders of magnitude. All experiments can be rationalized by introducing a hydrodynamical Peclet number defined as the ratio between the lubrication stress induced by vibrations and granular pressure. The behavior of vibrated wet and dry granular materials can then be unified by assimilating the Hookean stress in dry media to the lubrication stress in suspensions.
\end{abstract}

PACS numbers: 83.80.Hj, 83.80.Fg, 47.57.Gc, 47.57.Qk

The mechanical properties of suspensions of nonBrownian particles, i.e. with dimensions above a few microns, control numerous natural phenomena such as mudslides, avalanches and debris flows. Such suspensions are, in addition, of prime importance in a wide range of industrial applications, particularly in civil engineering. Still, the physics of such suspensions is not totally clear, and features such as yield stress $[1,2]$, shear localization [3], shear thickening [4] or particles migration [5] remain highly debated.

In contrast with recent work on the flow of iso-dense suspensions of polystyrene beads in Newtonian fluids subjected to shear flow in a Couette cell [6], the present Letter focuses on concentrated gravitational suspensions, i.e. suspensions where particles are significantly denser than the suspending fluid [7-9]. Although such a situation is relevant for understanding natural systems, a major difficulty associated to such studies is that the initial state of the suspension at rest cannot be properly defined as the system may be jammed far from equilibrium. As a consequence, the fine details of the low shear regime remain poorly understood as well as the mechanisms of the jamming-unjamming transition operating when the suspension starts flowing. To overcome such a drawback, we analyze the flow behavior of our gravitational suspensions under coupled vibrations and shear. Indeed, such a combination has proven extremely relevant for studying dry granular media $[10,11]$ in a wide range of shear. At low shear, dynamics appear to be controlled by vibrations, which yields a Newtonian behavior where granular reorganization is Brownian-like [10, 12, 13], whereas at high shear, dynamics can be described by a Coulombian law, where the main interactions between grains are frictional.

In the present Letter, we then investigate in details the flow behavior of gravitational suspensions subjected to coupled vibrations and shear. We show that applying any finite amplitude vibration suppresses the yield stress of gravitational suspensions that, under vibration, behave as viscous fluids. Their viscosity varies with particle size, suspending fluid viscosity, and vibration amplitude and frequency. All variations can be rationalized by introducing a Peclet number defined as the ratio between local lubrication and granular pressure.

We first analyze the rheological behavior of a dense gravitational suspension (volume fraction $\phi \approx 0.61$ ) composed of non-colloidal $100 \mu \mathrm{m}$ mono-disperse spherical glass beads (Whitehouse Scientist, $\rho_{p} \approx 2400 \mathrm{~kg} / \mathrm{m}^{3}$ ) immersed in a Newtonian fluid (Emkarox- water mixture $\left.\eta_{f}=67.8 \mathrm{mPa} . \mathrm{s}, \rho_{f} \approx 1032 \mathrm{~kg} / \mathrm{m}^{3}\right)$ subjected to simultaneous shear and vibrations and compare it to the behavior of the same dry beads. For this, we use a stressimposed rheometer (AR 2000, TA Instruments) coupled with a vibration exciter [10]. The geometry used is a four blades vane device (10 $\mathrm{mm}$ radius; $30 \mathrm{~mm}$ lenght) installed into a cylindrical baffled cell (25 mm radius; 5 $\mathrm{mm}$ baffle width). The characterization cell is analogous to a virtual Couette cell with an annular gap equal to 10 $\mathrm{mm}$. The distance between the bottom of the vane and the bottom of the cell is also equal to $10 \mathrm{~mm}$. Experiments were carried out at imposed shear stress (from 1 to $10^{3} \mathrm{~Pa}$ ) under sinusoidal vibrations. The measured shear rate ranges from $10^{-3}$ to $4.10^{2} \mathrm{~s}^{-1}$. All data points were obtained at steady state. In such a system, the mechanical vibration stress $\sigma_{v}$ can be defined as the mechanical energy per unit volume of a harmonic oscillator of the same mass as the sample [10], hence $\sigma_{v}=1 / 2 \rho A^{2}(2 \pi f)^{2}$ where $\rho$ is the density of the system $\left(\mathrm{kg} / \mathrm{m}^{3}\right)$, and $A$ and $f$ are the amplitude and frequency of vibrations, respectively. The vibration amplitude and frequency used vary 

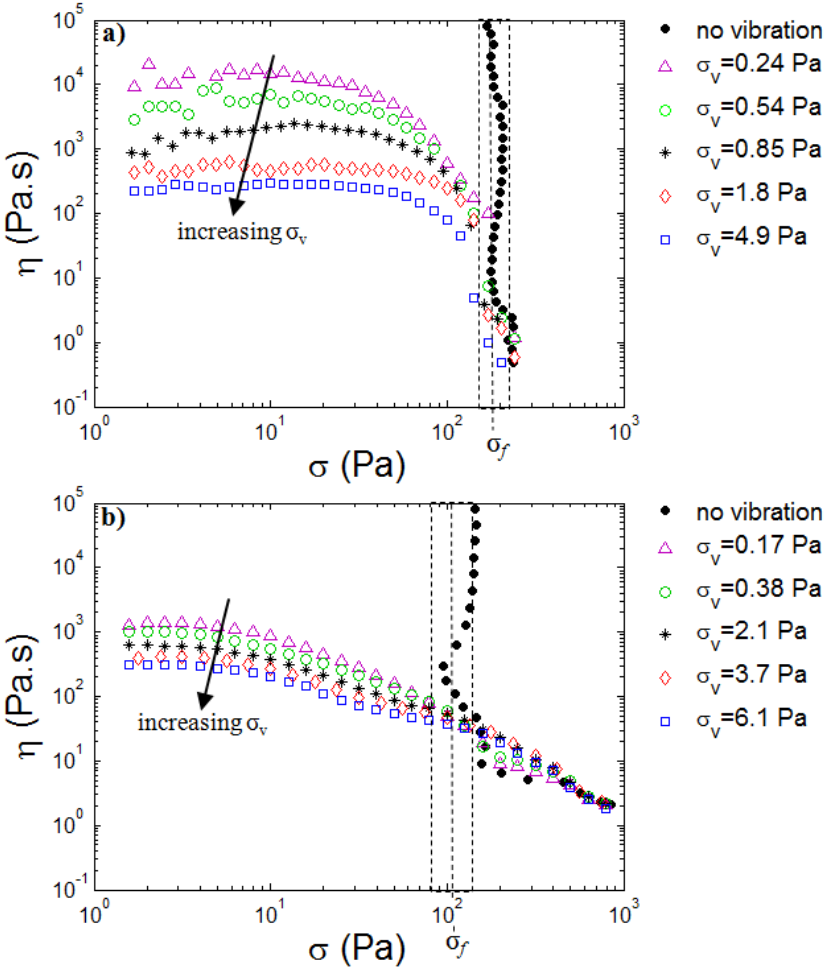

FIG. 1. (color online) Viscosity $(\eta)$ versus shear stress $(\sigma)$, for various values of vibration stress $\left(\sigma_{v}\right)$. (a) $100 \mu \mathrm{m}$ dry glass beads, $\phi \approx 0.62[10]$. (b) $100 \mu \mathrm{m}$ glass beads immersed in a $67.8 \mathrm{mPa} . \mathrm{s}$ Emkarox-water mixture, $\phi \approx 0.61$. Experiments were carried out at imposed shear stress (from 1 to $10^{3} \mathrm{~Pa}$ ), except for the curve at $\sigma_{v}=0$ (filled symbols) that was performed at imposed shear rate (from $10^{-3}$ to $4.10^{2} \mathrm{~s}^{-1}$ ). The dotted rectangle represents the range of values obtained for the calculation of the frictional stress $\sigma_{f}$ by Coulomb's law.

from 20 to $400 \mu \mathrm{m}$ and from 10 to $80 \mathrm{~Hz}$, respectively [14].

Figure 1 presents the evolution of the sample viscosity, $\eta$, as a function of the applied shear stress, $\sigma$, for various values of $\sigma_{v}$ for the dry (Fig. 1(a)) and wet (Fig. 1(b)) cases. In the dry case, for $\sigma_{v}=0$ (filled symbols in Fig. $1(\mathrm{a})), \sigma$ remains constant for all imposed shear rates. This regime is a Coulombian frictional one as shown by Marchal et al. [10]. The frictional stress, $\sigma_{f}$, is thus given by Coulomb's law, $\sigma_{f}=\mu P_{g}$, where $P_{g}$ is the average granular pressure defined by [10]:

$$
P_{g}=\Delta \rho \phi g z
$$

where $\Delta \rho$ is the relative density of the beads and fluids, $\phi$ the volume fraction, $g$ the gravitational constant 9.81 $\mathrm{m} . \mathrm{s}^{-2}$ and $z$ is an average height $(z=0.025 \mathrm{~m})[10]$. In the present case, for $\phi \approx 0.62$ and $\mu \approx 0.5$ [10], the application of Coulomb's law yields $\sigma_{f}=182 \pm 41 \mathrm{~Pa}$, in agreement with the experimental value. For wet granular media in the absence of vibration (filled symbols in Fig. 1(b)), a typical yield stress behavior is observed in agreement with previous results $[6,8,9]$. Application of
Eq. 1 yields a value of $103 \pm 22 \mathrm{~Pa}$, in agreement with experimental results. The lower value compared to the dry case is directly related to the density difference between air and Emkarox solution [15].

$\sigma_{f}$ represents a clear limit between two domains. For $\sigma \geq \sigma_{f}$, all viscosity curves follow the non-vibrated case whatever the mechanical vibration energy. In this regime, the flow behavior of the suspension is then fully controlled by shear stress, and the system behaves as classical Brownian (e.g. [16]) or non Brownian suspensions $[6,9,17]$. To further evidence such a statement, we analyze the dependence of $\eta_{300}$, the suspension viscosity measured for an applied shear stress of $300 \mathrm{~Pa}$, on suspending fluid viscosity $\eta_{f}[18]$, bead size $D$ and volume fraction $\phi$. Fig. 2(a) confirms that $\eta_{300}$ is proportional to $\eta_{f}$ and independent of bead size for sizes ranging between 49 and $530 \mu \mathrm{m}$. Fig. 2(b) shows that, in the case of 100 $\mu \mathrm{m}$ beads, the volume fraction variation of viscosity is well accounted for by Quemada's law $\eta=\eta_{f}\left(1-\frac{\phi}{\phi^{*}}\right)^{-2}$ [19] where $\phi^{*}$ is the maximum packing fraction. In the case presented here, $\phi^{*}=0.68$, i.e an intermediate value between $\phi^{*}$ at rest $(0.63)$ and $\phi^{*}$ under infinite shear (0.72) [20] [21]. In that regime, the system is controlled by the balance between cohesion stress, $\sigma_{f}$ and applied shear stress, $\sigma$. The ratio of the two quantities can be used to define a viscous Peclet number, $P e_{\text {shear }}$, that scales as $\eta_{f} \dot{\gamma} / \sigma_{f}$. Such a quantity is analogous to the
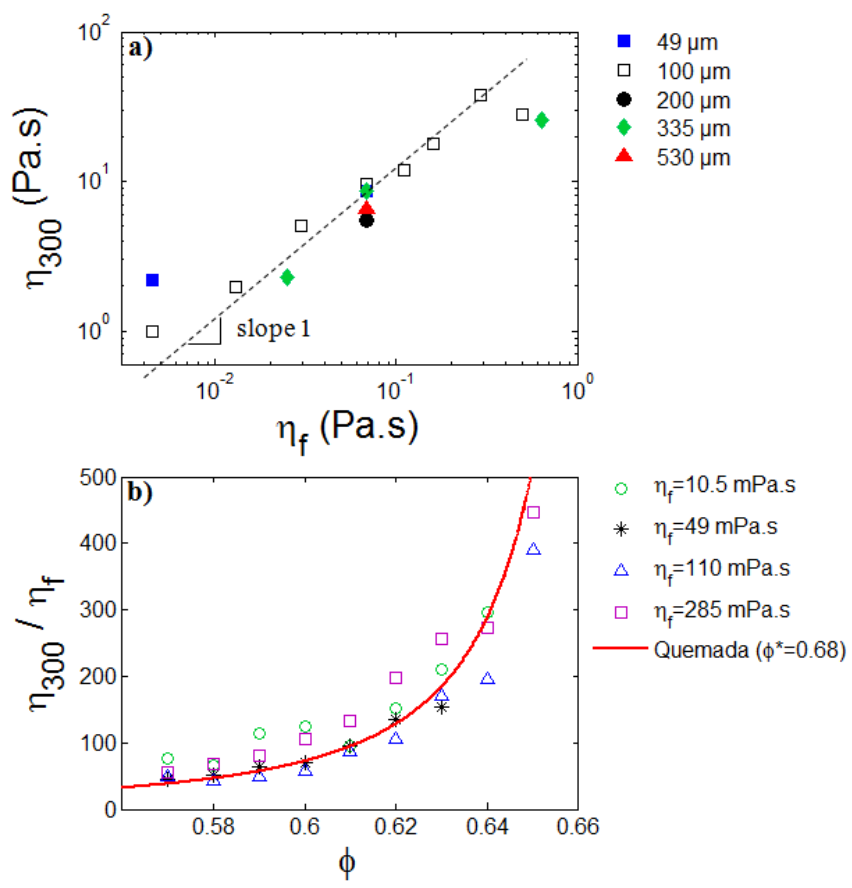

FIG. 2. (color online) $100 \mu \mathrm{m}$ glass beads immersed in various Emkarox-water mixtures. (a) High shear viscosity $\left(\eta_{300}\right)$ versus interstitial fluid viscosity $\left(\eta_{f}\right)$, for various values of bead size, $\phi \approx 0.61$. (b) Evolution with volume fraction, $\phi$, of $\eta_{300} / \eta_{f}$. 
Leighton number introduced by Coussot and co-workers $[8,9]$ to describe the transition from a frictional to a viscous regime in sheared dense suspensions and also to the viscous number introduced by Cassar et al [22] to describe the rheological behavior of submarine avalanches. In contrast the behavior observed for $\sigma \leq \sigma_{f}$ is much richer. Indeed, the suspension loses its yield stress and a viscosity plateau appears. This constant viscosity evidences mesoscopic motion in the system. The value of $\eta$ at the plateau depends on both vibration amplitude and frequency. The use of the vibration stress rationalizes all effects, higher stress leading to lower viscosity (Fig. 1). Such a behavior can be interpreted as resulting from an increase in particle mobility that, for both dry and wet materials, leads to lower cohesion. However, the nature of interactions in both cases is different as shown by the evolution of $\eta_{0}$, the viscosity at the plateau, with bead size. As shown in Fig. 3(a), in the dry case, the low shear viscosity plateau is rather independent of size, whereas a clear size dependence appears in the saturated suspension (Fig. 3(b)), higher size leading to higher viscosity. For dry materials, as previously shown [10], local interactions can be properly described on the basis of a Hookean approach, $\sigma_{d r y}=G \gamma$ where $G$ is an elastic modulus and $\gamma$ the deformation. In the saturated suspension, the local interaction between two beads is rather controlled by lubrication that can be dimensionally expressed as:

$$
\sigma_{l u b} \propto \frac{\eta_{f} A(2 \pi f)}{D}
$$

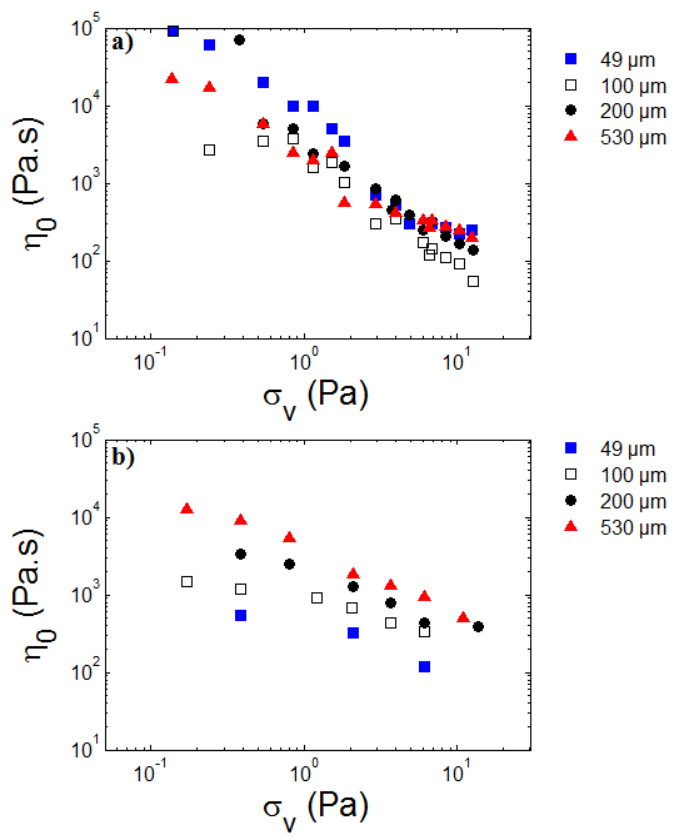

FIG. 3. (color online) Low shear viscosity plateau $\left(\eta_{0}\right)$ versus vibration stress $\left(\sigma_{v}\right)$, for various values of bead size. (a) Dry glass beads, $\phi \approx 0.62$ [10]. (b) Glass beads immersed in a $67.8 \mathrm{mPa} . \mathrm{s}$ Emkarox-water mixture, $\phi \approx 0.61$.
According to such an interpretation, in addition to size effects, changes in the viscosity of the suspending fluid should also have a direct influence on the value of $\eta_{0}$. To test for such an assumption, we then used the previously mentioned Emkarox-water mixtures. As shown in Fig. 4(a), at low shear, for constant vibration stress, an increase in $\eta_{f}$ leads to a significant decrease in the plateau viscosity $\eta_{0}$. Fig. 4(b) summarizes all these effects by plotting $\eta_{0}$ as a function of $\eta_{f}$ for various sizes and vibration stresses. In agreement with equation 2 , an increase in either vibration energy or fluid viscosity or a decrease in particle size leads to a decrease in $\eta_{0}$.

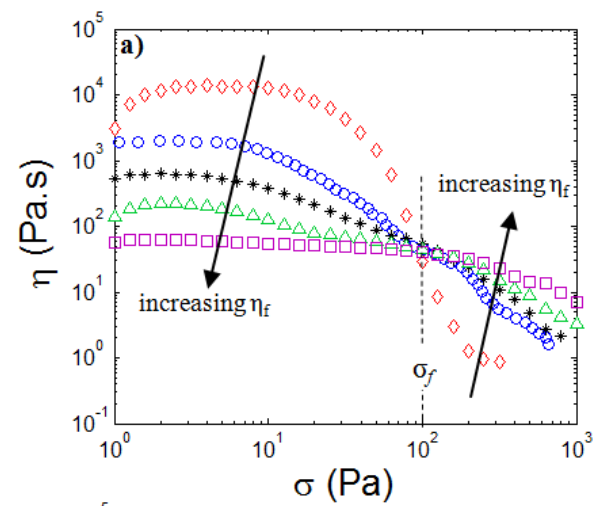

$$
\begin{array}{ll}
\diamond & \eta_{f}=4.5 \mathrm{mPa} . \mathrm{s} \\
0 & \eta_{\mathrm{f}}=30 \mathrm{mPa} . \mathrm{s} \\
* & \eta_{\mathrm{f}}=68 \mathrm{mPa} . \mathrm{s} \\
\Delta & \eta_{\mathrm{f}}=160 \mathrm{mPa} . \mathrm{s} \\
\square & \eta_{\mathrm{f}}=500 \mathrm{mPa} . \mathrm{s}
\end{array}
$$

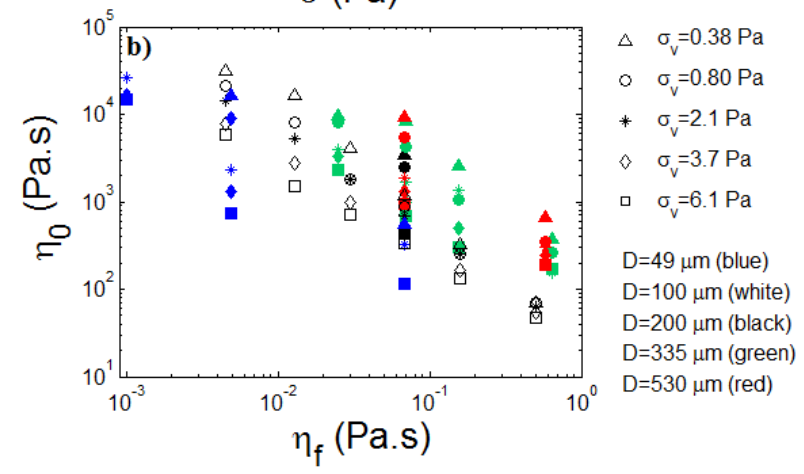

FIG. 4. (color online) (a) Viscosity $(\eta)$ versus shear stress $(\sigma)$, for various values of interstitial fluid viscosity, for 100 $\mu \mathrm{m}$ glass beads immersed in various Emkarox-water mixtures, $\phi \approx 0.61, \sigma_{v}=6.1 \mathrm{~Pa}$. (b) Low shear viscosity plateau $\left(\eta_{0}\right)$ versus interstitial fluid viscosity $\left(\eta_{f}\right)$, for various values of bead size and vibration stress, $\phi \approx 0.61$.

In that context, the low shear rheological behavior of gravitational suspensions is governed by the competition between the granular pressure $P_{g}$ (Eq. 1), that ensures the internal cohesion of the system and the lubrication stress, $\sigma_{l u b}$ (Eq. 2). This stress provides more degrees of freedom to the particles in the same way as the shear stress for values larger than $\sigma_{f}$. It is then relevant to define a lubrication Peclet number, $P e_{l u b}$ that scales as $\frac{\eta_{f} A(2 \pi f)}{D \sigma_{f}}$. In energetic terms, this Peclet number compares viscous dissipation energy to the internal cohesion energy of the system. Figure 5 displays a plot of $\eta_{0}$ as 


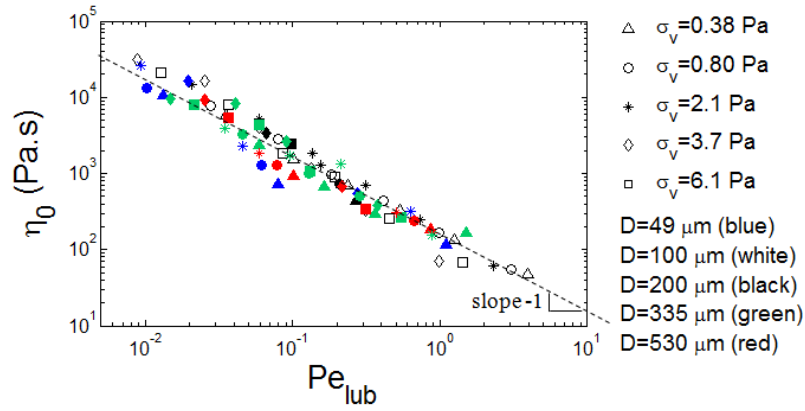

FIG. 5. (color online) Low shear viscosity plateau $\left(\eta_{0}\right)$ versus Peclet number $\left(P e_{l u b}\right)$, for various values of bead size, vibration stress and suspending fluid viscosity.

a function of $P e_{l u b}$. All points of Fig. 4(b) fall onto a master curve with a slope -1 , extending over more than two decades in both $P e_{l u b}$ and $\eta_{0}$, which validates the proposed approach [23].

Such a result has to our knowledge never been observed in gravitational suspensions and opens new perspectives in the study of granular media. In particular, the influence of vibrations on gravitational suspensions rheology may provide crucial information for understanding natural phenomena such as landslide triggering through earthquakes. In fundamental terms, the fact that any finite amplitude vibration is able to fluidize a jammed system may shed new light on the jamming-unjamming transition. Indeed, it challenges the classical assertion that considers that unjamming occurs only when the system is provided with an energy larger than its cohesive energy. In that context, a quantitative interpretation of the -1 decay observed in Fig. 5 clearly deserves deeper investigation. Indeed, if vibration increases the degrees of freedom of the particles, an exponential behavior would have been expected, by analogy with studies on viscosity of molecular liquids [24]. The unexpected trend observed in the present letter strongly suggests that the analogy between temperature and vibration is not trivial. It is then of prime importance to study in detail how vibration affects particles reorganization at both the local and semi-local scale as shown by recent experiments on load-bearing bridges [25]. It would be particularly relevant to experimentally investigate the dynamics of particles under increasing vibration energy. This could be achieved by carrying out fast tomography experiments such as those recently developed in synchrotron facilities or dynamic light scattering experiments currently under development.

\footnotetext{
* caroline.hanotin@ensem.inpl-nancy.fr
}

† christophe.baravian@ensem.inpl-nancy.fr

[1] A. Fall, F. Bertrand, G. Ovarlez, and D. Bonn, Phys. Rev. Lett. 103, 178301 (2009)

[2] G. Ovarlez, F. Bertrand, and S. Rodts, J. Rheol. 50, 259 (2006)

[3] J. F. Brady and J. F. Morris, J. Fluid. Mech. 348, 103 (1997)

[4] A. Fall, N. Huang, F. Bertrand, G. Ovarlez, and D. Bonn, Phys. Rev. Lett. 100, 018301 (2008)

[5] J. F. Morris and F. Boulay, J. Rheol. 43, 1213 (1999)

[6] N. Huang, G. Ovarlez, F. Bertrand, S. Rodts, P. Coussot, and D. Bonn, Phys. Rev. Lett. 94, 028301 (2005)

[7] J. A. Dijksman, E. Wandersman, S. Slotterback, C. R. Berardi, W. D. Updegraff, M. van Hecke, and W. Losert, Phys. Rev. E 82, 060301 (2010)

[8] P. Coussot and C. Ancey, Phys. Rev. E 59, 4445 (1999)

[9] P. Coussot and C. Ancey, Comptes rendus de lAcadmie des Sciences Paris Serie IIb 327, 515 (1999)

[10] P. Marchal, L. Choplin, and N. Smirani, J. Rheol. 53, 1 (2009)

[11] J. A. Dijksman, G. H. Wortel, L. T. H. van Dellen, O. Dauchot, and M. van Hecke, Phys. Rev. Lett. 107, 108303 (2011)

[12] G. D'Anna and G. Gremaud, Phys. Rev. Lett. 87, 254302 (2001)

[13] P. Mayor, G. D'Anna, A. Barrat, and V. Loreto, New J. Phys. 7, 28 (2005)

[14] In studies dealing with vibrated dry granular media $[12,13]$, the vibration is often characterized by the socalled acceleration number $\Gamma$ defined as $A(2 \pi f)^{2} / g$. For comparison purposes, our experiments extend over $\Gamma$ values ranging between 0.2 and 2.6.

[15] Such a dependence was further verified by using water/potassium iodomercurate dihydrate mixtures as suspending fluids.

[16] I. M. Krieger and T. J. Dougherty, Trans. Soc. Rheol. 3, $137(1959)$

[17] F. Boyer, E. Guazzelli, and O. Pouliquen, Phys. Rev. Lett. 107, 188301 (2011)

[18] $\eta_{f}$ was adjusted between $1 \mathrm{mPa}$.s and $500 \mathrm{mPa}$.s by using various Emkarox-water mixtures.

[19] D. Quemada, Rheol. Acta 16, 82 (1977)

[20] W. B. Russell, D. A. Saville, and W. R. Schowalter, Colloidal Dispersions (Cambridge University Press, Cambridge, 1992)

[21] As recently proposed [17], data could also be fitted using Krieger-Dougherty law [16] $\eta=\eta_{f}\left(1-\frac{\phi}{\phi^{*}}\right)^{-q}$ with $\phi^{*}=0.66$ and $q=1.65$. However the fit thus obtained is less convincing.

[22] C. Cassar, M. Nicolas, and O. Pouliquen, Phys. Fluids 17, 103301 (2005)

[23] It must be pointed out that this approach is only valid for Reynolds numbers smaller than one, i.e. when viscous effects dominate over inertial ones. This local Reynolds number can be expressed as $\frac{A(2 \pi f) D \Delta \rho}{\eta_{f}}$.

[24] A. K. Doolittle, J. Appl. Phys. , 22, 1031 (1951); 22, 1471 (1951); 23, 236 (1952); 23, 418 (1952); 28, 901 (1957)

[25] M. C. Jenkins, M. D. Haw, G. C. Barker, W. C. K. Poon, and S. U. Egelhaaf, Phys. Rev. Lett. 107, 038302 (2011) 